\title{
Um intelectual para o Brasil do passado e do presente: Caio Prado Júnior
}

\author{
An intellectual mind for Brazil's both past and present: Caio \\ Prado Júnior
}

\author{
Joelson Lopes Maciel*
}

PERICÁS, Luiz Bernardo. Caio Prado Júnior: uma biografia política. 1. ed. São Paulo: Boitempo, 2016.

Em 1966, o quarto agraciado com o Troféu Juca Pato de intelectual do ano, concedido pela União Brasileira de Escritores (UBE), foi o historiador paulistano Caio Prado Júnior. A publicação que o credenciou à disputa do prêmio foi A Revolução Brasileira (São Paulo: Brasiliense, 1966), que discutia os possíveis rumos das esquerdas no Brasil num momento candente, na esteira do golpe de 1964. Cinquenta anos depois, em 2016, o mesmo Troféu é conferido a outro historiador, Luiz Bernardo Pericás, por seu livro Caio Prado Júnior: uma biografia politica (São Paulo: Boitempo, 2016). É sobre esta obra que se debruça o presente texto.

Luiz Bernardo Pericás é graduado pela George Washington University (1992), doutor em História Econômica (USP - 1997) e pós-doutor em Ciência Política pela Faculdad Lationamericana de Ciencias Sociales - FLACSO/ México (2003) e também pelo Instituto de Estudos Brasileiros da USP - IEB/ USP. Compõe atualmente o corpo docente da Universidade de São Paulo, como professor de História Contemporânea.

* Mestrando no Programa de Pós-Graduação em História da Universidade Federal de Santa Catarina, Florianópolis/SC, Brasil. E-mail: joelsonlopesm@gmail.com

(c) EY Direito autoral e licença de uso: Este artigo está licenciado sob uma Licença Creative Commons. Com essa licença você pode compartilhar, adaptar, para qualquer fim, desde que atribua a autoria da obra, forneça um link para a licença, e indicar se foram feitas alterações. 
Sua vinculação acadêmica com o IEB/USP e com o Instituto Caio Prado Júnior - ICP (onde integra o conselho consultivo) proporcionou acesso privilegiado a Pericás para reunir milhares de documentos por ele analisados ao longo de vários anos de pesquisa. Apenas no acervo do IEB/USP existem 17414 documentos referentes ao biografado, dentre os quais centenas de correspondências (outras, ainda, no acervo particular de Danda Prado), artigos publicados em jornais, ofícios, entre outros. As fontes documentais consultadas por Pericás são numerosas e em grande parte inéditas. Além do acervo do IEB/ USP, contou o autor com depoimentos de pessoas ligadas a Caio Prado (sessenta e sete ao todo, entre 2008 e 2015). Foram consultados ainda cento e sessenta e sete periódicos ao todo. Por fim, a pesquisa iconográfica levou Pericás à acervos particulares e outros, incluindo o do Arquivo Público de São Paulo e o da Assembleia Legislativa de São Paulo. As inúmeras notas inseridas dentro do texto, e que geralmente remetem a um documento consultado, reforçam a força da pesquisa documental em que está calcada a biografia (essas notas, reunidas no fim do livro, ocupam nada menos que cento e dezoito páginas!).

Vale lembrar que esta biografia não é o primeiro esforço de Pericás tratando da reflexão sobre o pensamento brasileiro, e também não é sua estreia em relação à trajetória de Caio Prado: organizou, em parceria com Lincoln Secco, Intérpretes do Brasil: clássicos, rebeldes e renegados (São Paulo: Boitempo, 2014), onde divide autoria do capítulo Caio Prado Júnior com Maria Célia Wider. A presente biografia é a culminância do interesse de Pericás pela trajetória de seu colega paulista.

Em relação à escrita biográfica, seu lugar dentro da historiografia é hoje tema de debate em nosso campo. Cabe então breve contextualização: próximas desde a infância na Antiguidade Clássica, Biografia e História distanciaramse com o passar dos séculos, mas os séculos XIX e XX assistiram a uma reaproximação entre si, de acordo com as características teórico-metodológicas da disciplina histórica nestes períodos. É, porém, a partir da década de 1980 que nota-se um movimento de "retorno" das biografias, sob a égide da "história problema" dos Annales. A reabilitação das análises qualitativas e outro "retorno", o da história política, guardam sua contribuição. O trânsito dos historiadores brasileiros por espaços internacionais foi um dos fatores que ajudou a trazer para a nossa academia os debates (especialmente de franceses e italianos) em relação ao indivíduo, nos anos 1980 e 1990 - junto também com reflexões em relação à Memória, História oral e acervos pessoais. Fatores que criaram um "clima de receptividade" à biografia na academia nacional. ${ }^{1}$

É neste prolífico momento de produção de biografias no meio acadêmico brasileiro que se insere o presente trabalho de Luiz Bernardo Pericás. Embora o autor não entre no debate do papel das biografias dentro do campo da História na atualidade, indica em certos trechos sua proposta de construção do personagem: 
Este trabalho, portanto, tem como objetivo principal realizar uma discussão eminentemente política da trajetória do autor de Dialética do conhecimento, mostrando sua militância, sua leitura de clássicos marxistas, suas viagens, sua atitude em relação ao golpe militar, os debates sobre a revolução brasileira, seus tempos na prisão, sua relação com intelectuais contemporâneos, assim como apresentar elementos teóricos de seu ideário e o desenvolvimento do pensamento caiopradiano ao longo das décadas. ${ }^{2}$

Deste trecho, pode-se interpretar que para Pericás, Caio Prado Júnior é um indivíduo em constante construção, através de suas leituras, viagens e discussões, bem como é um indivíduo que atua sobre o meio em que se encontra, tanto pela via intelectual (livros e artigos publicados, conferências proferidas), quanto pela via militante (por décadas fora membro do PCB, sendo inclusive parlamentar durante o breve período de legalidade do Partidão na década de 1940). Militante e acadêmico são indissociáveis: Caio exerceu influência nos círculos do socialismo nacional e internacional através de seus escritos científicos, e muitas vezes pagou por isso com o ostracismo a que foi relegado pelos próprios camaradas em determinadas ocasiões.

Ao propor um indivíduo em construção, o biógrafo previne-se do que Pierre Bourdieu chama de "ilusão biográfica", em linhas gerais, uma crença de que uma trajetória é dotada de sentido e regida por um projeto definido de vida. Crença geralmente frisada no uso de termos como "desde pequeno", "sempre", "desde então", e outros, que imputam à personagem estudada gostos, aptidões e visões de mundo imutáveis ou então predestinadas ao sucesso ou ao fracasso. ${ }^{3}$

Luiz Bernardo Pericás também indica conjunturas políticas, aludindo ao golpe de 1964 (trabalha com inúmeros outros). Neste ponto, deve-se frisar o papel do contexto (incluindo aí o político) na construção de uma biografia, ou seja, a relação indivíduo/sociedade. Schmidt sintetiza em linhas gerais este debate:

Tentando superar esse dualismo, creio ser interessante pensar o contexto como um "campo de possibilidades historicamente delimitadas" (Ginzburg, 1989, p. 183) e lembrar que os indivíduos biografados - como qualquer indivíduo -, a cada momento de suas vidas, têm diante de si um futuro incerto e indeterminado, diante do qual fazem escolhas, seguem alguns caminhos e não outros. Se hoje esse futuro já é passado, e o resultado das escolhas feitas conhecido, o biógrafo tem a tarefa de recuperar o "drama da liberdade" (ver Berlin, 2002) dos personagens - as incertezas, as oscilações, as incoerências e, por que não?, o papel do acaso-, mostrando que suas trajetórias não estavam 
predeterminadas desde o início. Parodiando Thompson, é necessário expressar o "fazer-se" do personagem ao longo de sua existência ${ }^{4}$.

Funcionando como um campo de possibilidades e constrangimentos, o contexto não é fatalista a ponto de cercear completamente a ação do personagem (afinal, Caíto era filho da elite paulistana e tornou-se comunista!): é neste espaço que o historiador deve estabelecer uma narrativa que demonstre a tensão entre o sujeito e seu campo. Neste ponto, é pertinente notar quão significativa pode ter sido a experiência pregressa como romancista do autor (Pericás publicou, por exemplo, Cansaço, a longa estação, São Paulo: Boitempo, 2012), para organizar uma narrativa que necessita imprimir a versatilidade de uma vida humana. Aliás, Schmidt (2004) comenta também a relação entre a literatura e biografias, e como os historiadores têm buscado inspiração na primeira para auxiliar, ao menos esteticamente, a escrita das segundas.

Caio Prado Júnior: uma biografia política estrutura-se em uma Introdução, doze capítulos, Conclusão e elementos pós-textuais (entre os quais uma Cronologia do biografado, recurso sempre útil ao leitor). Os capítulos, pautados em divisões temáticas e narrados em ordem cronológica, não são "burocráticos". A escolha de temas (e eventos da vida do biografado) para pautar os capítulos é um recurso do autor para fugir da formalidade cronológica. Luiz Bernardo imprime então dinamismo ao texto, não perdendo de vista os aspectos da militância política, carreira acadêmica, vida pessoal e estratégias e aventuras editoriais do personagem. Retrata estes e outros fragmentos da vida do sujeito com clareza textual. Os tópicos/eventos eleitos são relacionados tanto à militância política de Caio Prado Júnior quanto à sua produção acadêmica: assim, não deixa de promover um diálogo simultâneo entre ambos.

Sua Introdução está preocupada em contextualizar o surgimento do pensamento socialista na América no decorrer do século XIX e início do seguinte, bem como a São Paulo que conheceu o jovem Caio e o peso de ser um Prado.

No primeiro capítulo, foco na aproximação de Caíto (apelo de Caio Prado) com o PCB, seu distanciamento dos liberais e os novos contatos dentro dos círculos socialistas em São Paulo. O segundo é um sólido relato de seus diálogos teóricos, a forma como apreendeu os escritos de socialistas europeus e procurou aplica-los para tentar compreender a realidade brasileira (esse diálogo é transversal, aparecendo em todos os capítulos, à medida que Caíto publicava mais estudos). $O$ terceiro também enfoca sua aprendizagem na primeira viagem à União Soviética que resultou na publicação de URSS: um novo mundo (São Paulo, Companhia Editora Nacional, 1934).

Os capítulos quatro e cinco são exemplos da escolha por temas voltados à militância, sendo o quarto seu tempo na prisão, decorrente da repressão contra 
a Aliança Nacional Libertadora - ANL; no quinto, a redemocratização do Brasil na década de 1940 e o breve tempo do Caio Prado deputado estadual em São Paulo eleito pelo PCB figuram como temas centrais. Isto não inibe Pericás, porém, de prestar devida justiça à vida pessoal de seu biografado, que neste período divorciou-se de sua primeira esposa e casou-se novamente (além do relacionamento com os filhos, certa forma distanciado, devido ao cárcere e à separação).

A década de 1950 é retratada mais como uma virada de Caíto aos estudos filosóficos (a publicação de Dialética do Conhecimento é destacada) e gerência editorial e intelectual à frente da Revista Brasiliense; enquanto o início da década seguinte é marcado por suas últimas viagens ao bloco socialista, dentre os quais URSS, Alemanha Oriental, Cuba e China Popular; este período foi retratado nos capítulos seis e sete.

Nas páginas seguintes, a repressão que sofreu Caio Prado pelas forças policiais da ditadura instalada em 1964, sendo aprisionado mais de uma vez, e seu exílio no Chile aparecem; até que no último capítulo Pericás se debruça no período dos anos 1980, a última década vivida pelo intelectual marxista: relata os problemas de saúde e a paulatina retirada do meio acadêmico.

$\mathrm{Na}$ Conclusão, faz um balanço da trajetória política e intelectual de Caíto, buscando frisar como o Caio comunista e o Caio historiador são simbióticos, pois os estudos teóricos de um lado o impeliram a reivindicar certas mudanças na estrutura socioeconômica e política do país, à revelia tanto dos setores da burguesia nacional quanto do próprio PCB. Procura também reafirmar a atualidade do pensamento caiopradiano para se entender o Brasil do século XXI e o de outrora.

Ao analisar a biografia construída por Luiz Bernardo Pericás sob o aspecto da produção deste gênero na historiografia, pode-se dizer que é um exercício que tem seus méritos, especialmente ao pensar a o indivíduo como alguém em constante formação, alguém que age em seu meio (no caso de Caio através de seus posicionamentos como político e intelectual), e por ele é influenciado (como nas viagens aos países socialistas). Ou seja, considerando as diversas nuances de sua trajetória e não deixando de lado aspectos conjunturais, aquele campo de possibilidades e constrangimentos.

\section{Notas}

1 MONTEIRO RUFFATO, Katani Maria; ZALLA, Jocelito. Apresentação. Métis: História e Cultura, Caxias do Sul-RS, v. 15, n. 30, p. 9-11, jul./dez. 2016.

2 PERICÁS, Luiz Bernardo. Caio Prado Júnior: uma biografia política. 1. ed. São Paulo: Boitempo, 2016, p.27. 
$3 \mathrm{O}$ artigo encontra-se na coletânea organizada por Janaína Amado e Marieta de Moraes Ferreira: BOURDIEU, Pierre. A ilusão biográfica. In: AMADO, Janaína; FERREIRA, Marieta de Moraes (org.). Usos \& Abusos da História Oral. Rio de Janeiro, FGV, 1996.

4 SCHMIDT, Benito Bisso. Grafia da vida: reflexões sobre a narrativa biográfica. História Unisinos, São Leopoldo-RS, v. 8, n.10, p. 137, 2004.

Recebido em 12/04/2017

Aprovado em 17/05/2017 